\title{
Optimization of Joint Economic Lot Size Model for Vendor-Buyer with Exponential Quality Degradation and Transportation by Chimp Optimization Algorithm
}

\author{
Dana Marsetiya Utama $\mathbb{D}^{D}$, Shanty Kusuma Dewi $\mathbb{C}^{D}$, and Sri Kurnia Dwi Budi Maulana \\ University of Muhammadiyah Malang, Jl. Tlogomas No. 246, Malang 65144, East Java, Indonesia \\ Correspondence should be addressed to Dana Marsetiya Utama; dana@umm.ac.id
}

Received 19 June 2021; Revised 28 January 2022; Accepted 31 January 2022; Published 24 February 2022

Academic Editor: Harish Garg

Copyright ( 92022 Dana Marsetiya Utama et al. This is an open access article distributed under the Creative Commons Attribution License, which permits unrestricted use, distribution, and reproduction in any medium, provided the original work is properly cited.

\begin{abstract}
Freight transportation plays a critical role in improving company performance in the modern manufacturing industry. To reduce costs, companies must take advantage of the use of large vehicles. It caused fewer deliveries, but inventory costs and degradation quality are high. One of the joint economic lot size (JELS) problems in supply chain is Integrated Single-Vendor Single-Buyer Inventory Problem (I-SVSB-IP). This study developed the I-SVSB-IP model that considers raw materials' exponential quality degradation and transportation costs. The objective function of this research was to maximize the Joint Total Profit (JTP). Three decision variables used were inventory cycle time $(T)$, raw material ordering frequency $(m)$, and frequency of delivery of finished products to buyers $(n)$. This study proposed a sophisticated Chimp Optimization Algorithm (ChOA) procedure to solve the I-SVSB-IP problem. A case study on the food industry in Indonesia was presented to optimize the I-SVSB-IP. The results showed that the ChOA procedure had produced an optimal solution compared to the state-of-the-art algorithm. This study also demonstrated a sensitivity analysis of decision and transportation variables to cost, revenue, and JTP. The results show that increasing transport frequency of ordering raw materials $(\mathrm{m})$ and finished products to buyers $(\mathrm{n})$ enhances the total cost and reduces joint total profit. In addition, increasing the rate of quality degradation of raw materials reduces JTP.
\end{abstract}

\section{Introduction}

Currently, company performance is influenced by the effectiveness of supply chain management (SCM) [1-3]. SCM plays an essential role in integrating various company parts to increase competitive advantage $[4,5]$. SCM is an approach used to incorporate decisions from upstream to downstream to minimize costs in the system [6]. Several efforts are made to improve company performance, such as advanced continuous replenishment, continuous partnerships, quick response, and integrated inventory decision $[7,8]$. Integrated inventory is proven to have the best performance in many companies $[9,10]$. The freight transportation problem has a vital role in improving company performance [11]. In general, research on fuel reduction in freight transportation is interesting to investigate. One way to reduce fuel consumption is to minimize delivery frequency $[12,13]$. Companies need to take advantage of the use of large vehicles to increase vehicle utilization to reduce costs. This decision impacts the low frequency of delivery. However, the inventory costs incurred are high, causing high operating costs for the company [14-16]. In addition to transportation problems, the problem of decreasing quality is an important problem in inventory [17]. The decrease in the quality of raw materials impacts the quality of the finished product, which is not in accordance with company standards [18]. In addition, it also has an impact on high operational costs in the company. Excess raw material inventory causes degradation of raw material quality. Park [19] was the first researcher to develop an integrated production-inventory model for decaying raw materials. Unfortunately, this research assumes non-perishable raw materials. Many perishable products experience an exponential decline in quality. 
Joint economic lot size (JELS) problems are commonly used in the inventory literature to describe the problem of making joint lot sizing decisions involving multiple entities in a supply chain [20]. One of the JELS problems is integrating inventory management decisions at the vendor and buyer levels $[21,22]$. This problem is called the Integrated Single-Vendor Single-Buyer Inventory Problem (I-SVSB-IP) [23]. This problem has received wide attention from researchers $[24,25]$. One of the products that have unique characteristics is food product. Food products can degrade in both exponential and linear ways [26, 27]. Generally, some research studies assume that the degradation quality of raw materials is linear. However, in fact, some products have characteristics of exponential quality degradation. Furthermore, transportation costs in procurement and deliveries activities are rarely considered in the investigation. These costs influence total cost and profit, so transportation costs need to be studied in increasing company profits. In addition, in previous studies, research generally assumes that the demand for finished products is the same as the need for raw materials. However, for some products, the demand for raw materials is not the same as the demand for finished products.

Based on previous research, the I-SVSB-IP study that discussed exponential quality degradation and transportation costs for food products was not investigated. The proposed transportation cost model considers the transportation of raw material delivery and finished product delivery. This reason was the first motivation for this research. Some products with an exponential decrease in quality are categorized as perishable products $[28,29]$. Some of the products that suit these characteristics are food products [30], pharmaceuticals [31], and agricultural products [32]. In addition, several metaheuristic procedures have been offered for inventory optimization. Some of these algorithms include Genetic Algorithm (GA) [33-36], Particle Swarm Optimization (PSO) [37], PSO and GA [9], simulated annealing [38], Harmony Search (HS) [39], and Evolutionary Algorithm [40, 41]. Of the several proposed algorithms, the popular metaheuristic algorithms used to optimize the vendor-buyer inventory model problem are GA [33-36], PSO [37], and PSO and GA [9]. Unfortunately, no studies utilized the Chimp Optimization Algorithm (ChOA) to solve the I-SVSB-IP. The ChOA is a new sophisticated metaheuristic procedure that has been inspired by chimp behavior in food hunting [42]. In 2020, this algorithm was proposed by Khishe and Mosavi [42] to solve continuous problems. The ChOA has also been successfully applied for classification [43] and digital filters [44]. This reason is what motivates researchers to use a ChOA as an optimization tool for I-SVSBIPs.

The following two questions are addressed in this study, based on the findings of the previous gap analysis:

(1) How do transportation activities and exponential quality degradation affect the time/length during the inventory cycle and the total profit of the integrated Inventory system in the I-SVSB-IP?

(2) How to use and perform ChOA as an optimization tool for I-SVSB-IPs?
Therefore, this study offers the I-SVSB-IP model by involving exponential quality degradation and transportation costs. This study develops an exponential quality degradation raw material model from the research conducted by Fauza et al. [34]. As described above, their research considers linear quality degradation. The transportation costs considered in the I-SVSB-IP were the transportation costs for the procurement of raw materials and delivery of finished products. This study develops the transportation cost model proposed by Bonney and Jaber [45]. The decision variables of this study are inventory cycle time $(T)$, frequency of raw material ordering $(m)$, and frequency of delivery of finished products $(n)$. This study also considers the model that is converted from demand for finished products to raw materials. In addition, this study proposed the ChOA as an optimization tool to solve the I-SVSB-IP. Therefore, the contributions of this study are as follows. (1) It offers a new I-SVSB-IP model involving exponential quality degradation and transportation costs. (2) It proposes the ChOA as an optimization tool to solve problems.

The structure of this paper is presented as follows. Section 2 describes the literature review, and the characteristics of the system are presented in Section 3. Next, assumptions and notations are described in Section 4. Then, the mathematical model of the I-SVSB-IP system is discussed in Section 5, while the proposed algorithm for I-SVSB-IP is presented in Section 6. Next, Section 7 discusses data collection and experimental procedures, while the results and discussion are discussed in Section 8. Finally, the conclusion and suggestions are given in Section 9.

\section{Literature Review}

In this section, this article discusses the literature review in the field of I-SVSB-IPs. Researchers have published several I-SVSB-IP studies. Banerjee [46] is the first researcher to examine the I-SVSB-IP problem with one decision variable: lot size. In his research, the vendor had a role as a manufacturer. Furthermore, Goyal [47], Goyal and Gupta [48], Hill [49], and Lu [50] investigated a similar issue. Moreover, this model was developed by Hill and Omar [51] to determine the production and shipment policy. Ben-Daya and Raouf [52] developed a model taking the lead time into account. This model was developed by Ouyang et al. [53], involving backorders and lost sales. A model that considers continuous replenishment and just-in-time purchasing was proposed by Yao et al. [54]. A model involving multiple production setups and rework was proposed by Sekar and Uthayakumar [55]. In addition, a model that considered the lead times and stochastic demand was introduced by Mou et al. [56]. Meanwhile, AlDurgam et al. [57] developed a model with stochastic demand and variable production rates. A model considering the transport-inventory system was constructed by Zanoni and Zavanella [58].

Several studies on the I-SVSB-IP model with imperfect quality were also proposed. Lee and Kim [59] projected the I-SVSB-IP model by considering deteriorating and defective items. Liu et al. [60] suggested the I-SVSB-IP model with 
declining production and shipment policy items. A model considering learning effect, fuzzy demand, and imperfect quality were also proposed by $\mathrm{Fu}$ et al. [61]. Based on previous studies, research that discusses quality degradation is scarce. Only four papers were recorded discussing deteriorating and defective items as presented by Liu et al. [60], Fu et al. [61], Fauza et al. [34], and Lee and Kim [59]. A food product is one of the products that have unique characteristics. There are both linear and exponential degradation aspects of food products [26, 27]. Unfortunately, to our knowledge, only Fauza et al. [34] discussed the I-SVSB-IP model for food products. Their study assumes that raw material degradation quality is linear.

In addition, several studies included integrated vendorbuyer research involving transportation costs. Zanoni and Zavanella [58], Wangsa and Wee [62], and Wangsa et al. [63] have considered transportation costs in these studies. Transportation costs were considered in two recent studies by Wangsa and Wee [62] and Wangsa et al. [63]. However, neither of them considered the possibility of quality degrading at an exponential rate. Researchers in this field examined how products get from the manufacturer to the customer. Unfortunately, transportation costs for raw materials are not taken into account in the model they have created. The model with stochastic demand, defective items, and carbon emission cost was modeled by Jauhari [64]. The model with reliability, carbon emission, and inspection errors in a defective production system was developed by Sangal et al. [65]. Jauhari [66] formulated $i$ th defective items, inspection error, and stochastic demand. Recently, ÇömezDolgan et al. [67] proposed the I-SVSB-IP model, which involves untimely delivery. The model by considering the bounded production cycle length was offered by Herbon [68].

The comparison of this study with previous studies in I-SVSB-IP is presented in Table 1. It shows that the objective function of minimizing cost dominates the I-SVSB-IP problem. On the other hand, the objective function of profit maximization is still rarely investigated. In this study, transportation costs for procurement activities and delivery activities are considered. In addition, this research involves a decrease in the quality of raw materials and shelf-life-based price function for finished products at the buyer level. The ChOA is proposed as a sophisticated procedure to optimize this problem.

\section{System Characteristics}

The characteristics of the I-SVSB-IP are illustrated in Figure 1 . This figure displays that the raw material is purchased by a vendor (manufacturer). Vendors order raw material $m$ times to fulfill production demand with the amount of $D$ during the production cycle of $T$. Vendors use the mode of transportation to purchase raw material for $m$ times to the supplier. The total raw material required in production is $\lambda$. $D . \lambda$ is the conversion coefficient from finished goods to raw material. In raw material storage at vendors (manufacturers), raw materials decrease quality. Furthermore, raw materials are processed into finished products with a production level of $P$. The finished product is then sent to the buyer as many as $n$ times to fulfill the $D$ end customer's demand. Vendors use the mode of transportation to deliver finished products for $n$ times to buyers. At the storage of raw materials at the buyer level, the finished product decreases quality. The finished product also has an expiration date. As the expiration date approaches, the product has a cheaper selling price [29].

Figure 2 shows an inventory system on the I-SVSB-IP. Two types of materials studied in the I-SVSB-IP are raw materials and finished products. Vendors (manufacturers) procure raw materials from suppliers. The procurement quantity of raw materials for each shipment is $q r$. The raw material procurement cycle can be formulated as $q r / \lambda D$. Furthermore, the raw material needed to fulfill the demand for finished products $(D)$ is $\lambda D$, where $\lambda$ is the conversion coefficient of the conversion of raw materials to finished products. The company carries out production at a production rate of $P$. Therefore, the rate of raw material for production is $\lambda P$. During one inventory cycle, products are produced during the $T p$ period to fulfill buyer $D$. The number of finished products to meet the demand during the production cycle $T$ is denoted as $Q p=\mathrm{DT}$. Tp can be calculated with the DT/P formula. Furthermore, the finished product is shipped for $n$ times the number of batches of $q p$ size. Therefore, the cycle of ordering the finished product by the buyer can be calculated by $q p / D$.

\section{Assumptions and Notations}

This study uses assumptions based on the research of Fauza et al. [34] and Fauza et al. [29]. The assumptions used in the I-SVSB-IP are as follows: (1) raw material quality decreases exponentially during storage, (2) shortage and backorder are not allowed, (3) production rates and demand levels are constant, (4) load does not significantly affect fuel consumption, (5) production rate > demand rate, (6) delivery lead time is ignored, (7) the capacity of the vehicle is neglected, and (8) the rate of exponential degradation raw material for one cycle is 0 to 1 . The notations used in this model include the following:

$P$ : production rate for producing the finished product (units/month).

$D$ : number of demands for finished products (units/ month).

$\lambda$ : conversion coefficient of the finished product to raw material.

$q_{r}$ : the size of the raw material order (unit).

$q_{p}$ : finished product delivery size (unit).

$k$ : rate of quality degradation of raw materials (quality units/month).

$Q_{\text {max }}$ : maximum quality of raw material (quality units).

$Q_{\text {min }}$ : minimum quality of raw materials (quality units).

$Q(t)$ : remaining quality at time $t$ for raw material (quality units). 
TABLE 1: Comparison of this study with previous studies in I-SVSB-IP.

\begin{tabular}{|c|c|c|c|c|c|c|c|}
\hline \multirow[b]{2}{*}{ Author } & \multicolumn{2}{|c|}{ Transportation cost } & \multirow{2}{*}{$\begin{array}{c}\text { Quality } \\
\text { degradation/ } \\
\text { deterioration }\end{array}$} & \multirow{2}{*}{$\begin{array}{l}\text { Shelf-life- } \\
\text { based price } \\
\text { function }\end{array}$} & \multicolumn{2}{|c|}{ Objective function } & \multirow[b]{2}{*}{$\begin{array}{l}\text { Solution } \\
\text { procedure }\end{array}$} \\
\hline & $\begin{array}{c}\text { Procurement } \\
\text { activities }\end{array}$ & $\begin{array}{l}\text { Delivery } \\
\text { activities }\end{array}$ & & & $\begin{array}{l}\text { Minimize } \\
\text { total cost }\end{array}$ & $\begin{array}{c}\text { Maximize } \\
\text { profit }\end{array}$ & \\
\hline & - & - & - & - & $\mathrm{V}$ & - & Exact \\
\hline Goyal [47] & - & - & - & - & $\mathrm{V}$ & - & Exact \\
\hline Goyal and Gupta [48] & - & - & - & - & $\mathrm{V}$ & - & Exact \\
\hline Hill [49] & - & - & - & - & $\mathrm{V}$ & - & Heuristic \\
\hline $\mathrm{Lu}[50]$ & - & - & - & - & $\mathrm{V}$ & - & Heuristic \\
\hline Hill and Omar [51] & - & - & - & - & $\mathrm{V}$ & - & Heuristic \\
\hline $\begin{array}{l}\text { Ben-Daya and Raouf } \\
\text { [52] }\end{array}$ & - & - & - & - & $\mathrm{V}$ & - & Heuristic \\
\hline Ouyang et al. [53] & - & - & - & - & $\mathrm{V}$ & - & Heuristic \\
\hline Yao et al. [54] & - & - & - & - & $\mathrm{V}$ & - & Heuristic \\
\hline $\begin{array}{l}\text { Sekar and } \\
\text { Uthayakumar [55] }\end{array}$ & - & - & $\mathrm{V}$ & - & $\mathrm{V}$ & - & GA \\
\hline Mou et al. [56] & - & - & - & - & $\mathrm{V}$ & - & Heuristic \\
\hline AlDurgam et al. [57] & - & - & - & - & $\mathrm{V}$ & - & Heuristic \\
\hline $\begin{array}{l}\text { Banerjee [46], Liu et al. } \\
{[60]}\end{array}$ & - & - & $\mathrm{V}$ & - & $\mathrm{V}$ & - & Heuristic \\
\hline Fu et al. [61] & - & - & $\mathrm{V}$ & - & $\mathrm{V}$ & - & Heuristic \\
\hline Fauza et al. [34] & - & - & $\mathrm{V}$ & $\mathrm{V}$ & - & $\mathrm{V}$ & GA \\
\hline Lee and Kim [59] & - & - & $\mathrm{V}$ & - & - & $\mathrm{V}$ & Heuristic \\
\hline $\begin{array}{l}\text { Zanoni and Zavanella } \\
\text { [58] }\end{array}$ & - & $\mathrm{V}$ & - & - & $\mathrm{V}$ & - & Heuristic \\
\hline Wangsa and Wee [62] & - & $\mathrm{V}$ & - & - & $\mathrm{V}$ & - & Heuristic \\
\hline Wangsa et al. [63] & - & $\mathrm{V}$ & - & - & $\mathrm{V}$ & - & Heuristic \\
\hline $\begin{array}{l}\text { Çömez-Dolgan et al. } \\
\text { [67] }\end{array}$ & - & - & - & - & V & - & Heuristic \\
\hline Herbon $[68]$ & - & $\mathrm{V}$ & - & - & $\mathrm{V}$ & - & Heuristic \\
\hline Jauhari [64] & - & $\mathrm{V}$ & - & - & $\mathrm{V}$ & - & Heuristic \\
\hline Jauhari [66] & - & - & - & - & $\mathrm{V}$ & - & Heuristic \\
\hline This research & $\mathrm{V}$ & $\mathrm{V}$ & $\mathrm{V}$ & $\mathrm{V}$ & - & $\mathrm{V}$ & ChOA \\
\hline
\end{tabular}

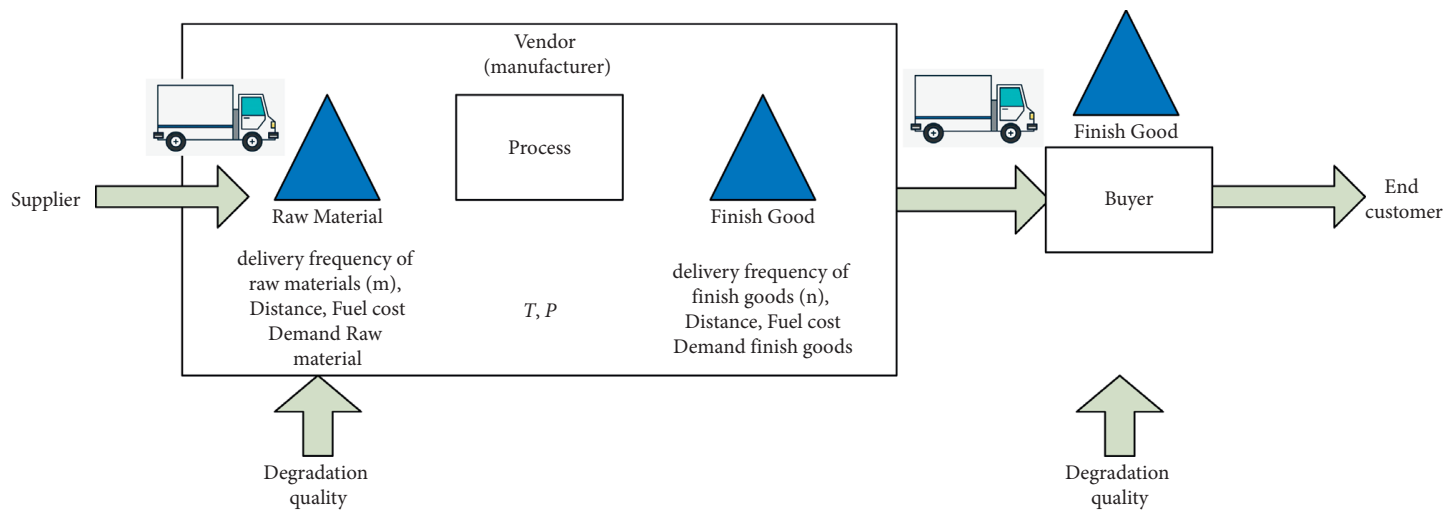

FIgURE 1: Characteristics of the I-SVSB-IP.

$c_{\text {loss }}$ : costs due to quality degradation of raw materials (rupiahs/quality units/month).

$c_{\text {sale }}$ : costs of purchasing finished products from buyers to vendors (rupiahs/order).

$c_{\mathrm{r}}$ : the cost of purchasing raw materials (IDR/order).

$c_{\mathrm{p}}$ : costs for processing the finished product (IDR/unit).
$A_{r}$ : transportation costs for the procurement of materials (IDR/order).

$A_{p}$ : transportation costs for the delivery of the finished product (IDR/delivery).

$a_{r}$ : fixed costs of raw material transportation (IDR/ order). 


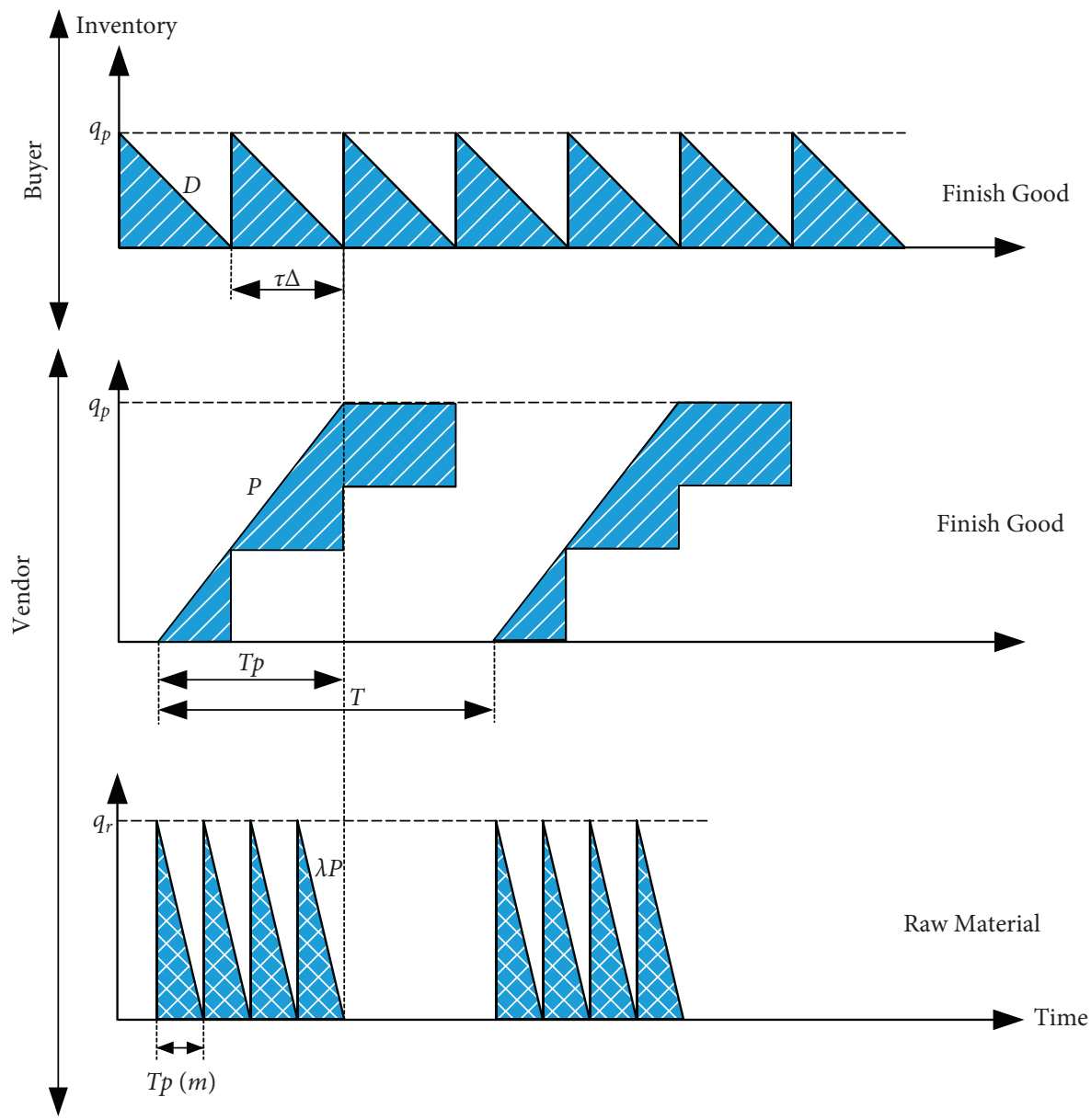

Figure 2: Inventory system on the I-SVSB-IP.

$a_{p}$ : fixed costs of transportation of the finished product (IDR/order).

$d_{r}$ : distance of raw material supplier to vendor (manufacture) $(\mathrm{km})$.

$d_{p}$ : distance from buyer to vendor (manufacture) $(\mathrm{km})$. $v_{r}$ : kilometers per liter for the procurement of raw materials $(\mathrm{km})$.

$v_{p}$ : kilometers per liter for delivery of finished products $(\mathrm{km})$.

$\beta r$ : the price of fuel used in raw material procurement activities (IDR per liter).

$\beta p$ : the price of fuel used in the delivery of the finished product (IDR per liter).

$T r$ : transportation costs for the procurement of raw materials (IDR/order).

$T p$ : transportation costs for the delivery of the finished product (IDR/order).

$S_{p}$ : installation costs for processing the finished product (IDR/month).

$H_{\mathrm{r}}$ : raw material storage costs (IDR/unit/month).

$H_{\mathrm{p}}$ : the cost of storing the finished product (IDR/unit/ month).
$I_{\mathrm{rm}}$ : average raw material inventory at vendors (unit). $I_{\mathrm{pm}}$ : the average finished product inventory at the vendor (unit).

$I_{\mathrm{pr}}$ : average finished product inventory at buyers (unit). $\tau_{\text {sl }}$ : the expiration time of the finished product (month).

$\tau_{\text {Start }}$ the initial time of the deterioration of the finished product (month).

$E_{\mathrm{i}}$ : batch $i$ product age when sent to the buyer (month). $R$ : total income (IDR/month).

$p_{\text {max }}:$ maximum product price (IDR/unit).

$p_{\text {min }}:$ minimum product price (IDR/unit).

$p(t)$ : product price in period $t$ (IDR/unit).

$L$ : total costs due to quality degradation of raw materials (IDR/month).

$T C_{\mathrm{rm}}$ : the total cost of the raw material inventory system at the vendor (IDR/month).

$T C_{\mathrm{pm}}$ : the total cost of the finished product inventory system at the vendor (IDR/month).

$T C_{\mathrm{pr}}$ : the total cost of the finished product inventory system at the buyer (IDR/month). 
JTP: the total profit of the integrated inventory system (IDR/month).

$m$ : frequency of ordering raw materials (times/order).

$T$ : time/length during the inventory cycle (month).

$n$ : delivery frequency of finished products to buyers (times/delivery).

\section{Mathematical Model}

This section describes the proposed mathematical model in the I-SVSB-IP. In the proposed model, the three components of the total cost to be considered include TCrm, TCpm, and TCpr. At TCrm, the cost of an exponential reduction in raw material quality is based on the model proposed by Rong et al. [69]. An illustration of the quality degradation is presented in Figure 3. If $k=1$, then the quality degradation is exponentially shown by line $B$ (first-order reaction). However, if $k=0$, the quality degradation is linearly represented by line $A$ (zero-order reaction). The total quality loss cost model per unit time $L(m, T)$ of raw material for all batches during one production cycle is presented in (1). Loss quality in the period 0 to $t$, namely, $Q \max$ to $Q(t)$, can be denoted by $\Delta Q(t)$ which is presented in (2). The quality level remaining at time $t$ is formulated as $Q(t)$ in (3).

$$
\begin{aligned}
L(m, T) & =c_{\operatorname{loss}} \frac{m \lambda P}{T} \int_{0}^{\lambda \mathrm{DT} / m \lambda P} \Delta Q(t) \mathrm{d} t \\
\Delta Q(t) & =Q_{\max }\left(1-e^{-k t}\right), \\
Q(t) & =Q_{\max } e^{-k t} .
\end{aligned}
$$

The model for transportation costs in the procurement of raw materials to suppliers is presented in (4). This model considers fixed transportation costs, distance, kilometers per liter, and fuel prices. The average raw material inventory at the vendor $\left(I_{r m}\right)$ can be seen in (5). Therefore, the total cost of the raw material inventory system at the vendor (manufacturer) level $\left(T C_{r m}(m, T)\right)$ is the sum of the costs of purchasing, transportation, inventory, and quality degradation as presented in (6).

$$
\begin{aligned}
T_{r}= & a_{r}+2 * \frac{d_{r}}{v_{r}} * \beta_{r} \\
I_{r m}= & \frac{\lambda D^{2} T}{2 m \lambda P}, \\
\mathrm{TC}_{r m}(m, T)= & c_{r} \lambda D+A_{r} \frac{m}{T}+\left(a_{r}+2 * \frac{d_{\mathrm{r}}}{v_{r}} * \beta_{r}\right) \frac{m}{T} \\
& +H_{r} \frac{\lambda D^{2} T}{2 m \lambda P}+c_{\mathrm{loss}} \frac{m \lambda P}{T} \int_{0}^{\lambda D T / m \lambda P} \Delta Q(t) \mathrm{d} t
\end{aligned}
$$

In the inventory model for finished products at the vendor level, the average finished product inventory at the vendor $\left(I_{p m}\right)$ is shown in (7). The total cost of the finished

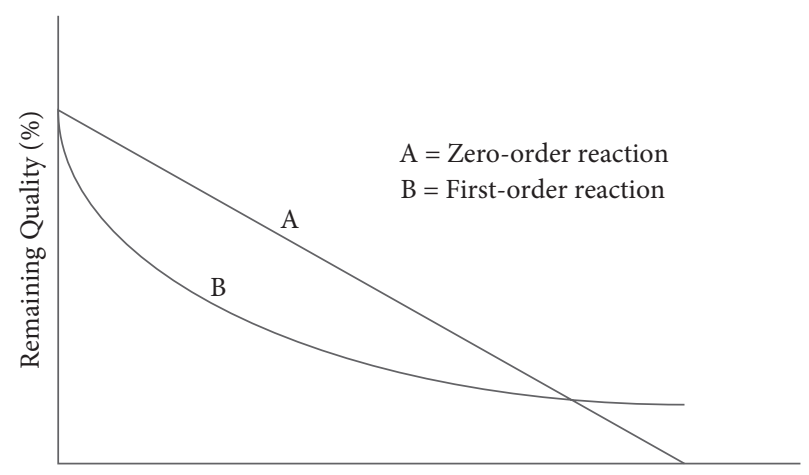

Time (days)

FIGURE 3: Illustration of product quality degradation.

product inventory system at the vendor includes production, setup, and inventory costs which are formulated in (8).

$$
\begin{aligned}
I_{p m} & =\frac{\mathrm{DT}}{2 n}\left(\frac{D}{P}(2-n)+(n-1)\right) \\
\mathrm{TC}_{p m}(n, T) & =c_{p} D+\frac{S}{T}+H_{p}\left(\frac{\mathrm{DT}}{2 n}\left(\frac{D}{P}(2-n)+(n-1)\right)\right) .
\end{aligned}
$$

In the total cost of the finished product inventory system at the buyer $\left(T C_{p r}(n, T)\right)$, the total cost also considers order, purchase, transportation, and inventory costs. The average finished product inventory at buyers $\left(I_{p r}\right)$ can be seen in (9). The transportation cost model for the delivery of finished products is formulated in (10). Furthermore, the total cost of the finished product inventory system at the buyer is shown in (11).

$$
\begin{aligned}
I_{p r}= & \frac{\mathrm{DT}}{2 n}, \\
T_{p}= & a_{p}+2 * \frac{d_{p}}{v_{p}} * \beta_{p}, \\
\mathrm{TC}_{p r}(n, T)= & c_{\text {sale }} D+A_{p} \frac{n}{T}+\left(a_{p}+2 * \frac{d_{p}}{v_{p}} * \beta_{p}\right) \frac{n}{T} \\
& +H_{p}\left(\frac{\mathrm{DT}}{2 n}\right) .
\end{aligned}
$$

To model revenue, buyers set prices in three areas. It is based on the customer's willingness to pay for the purchase of a product which will decrease linearly or exponentially as the expiration date approaches [70]. Since the product is sent to the retailer as many as $n$ shipments during the production cycle, the quality of the product in each batch may not be the same. The price of the product in each batch is different according to the age of the batch before being shipped. Price function based on the shelf life of each batch is illustrated in Figure 4 . The three areas include before quality degradation of the $\tau$ Start, remaining stock sold at a discount, and expired products. The product price for products before quality degradation $\tau$ Start is the maximum price of $p_{\max }$ (region I). 


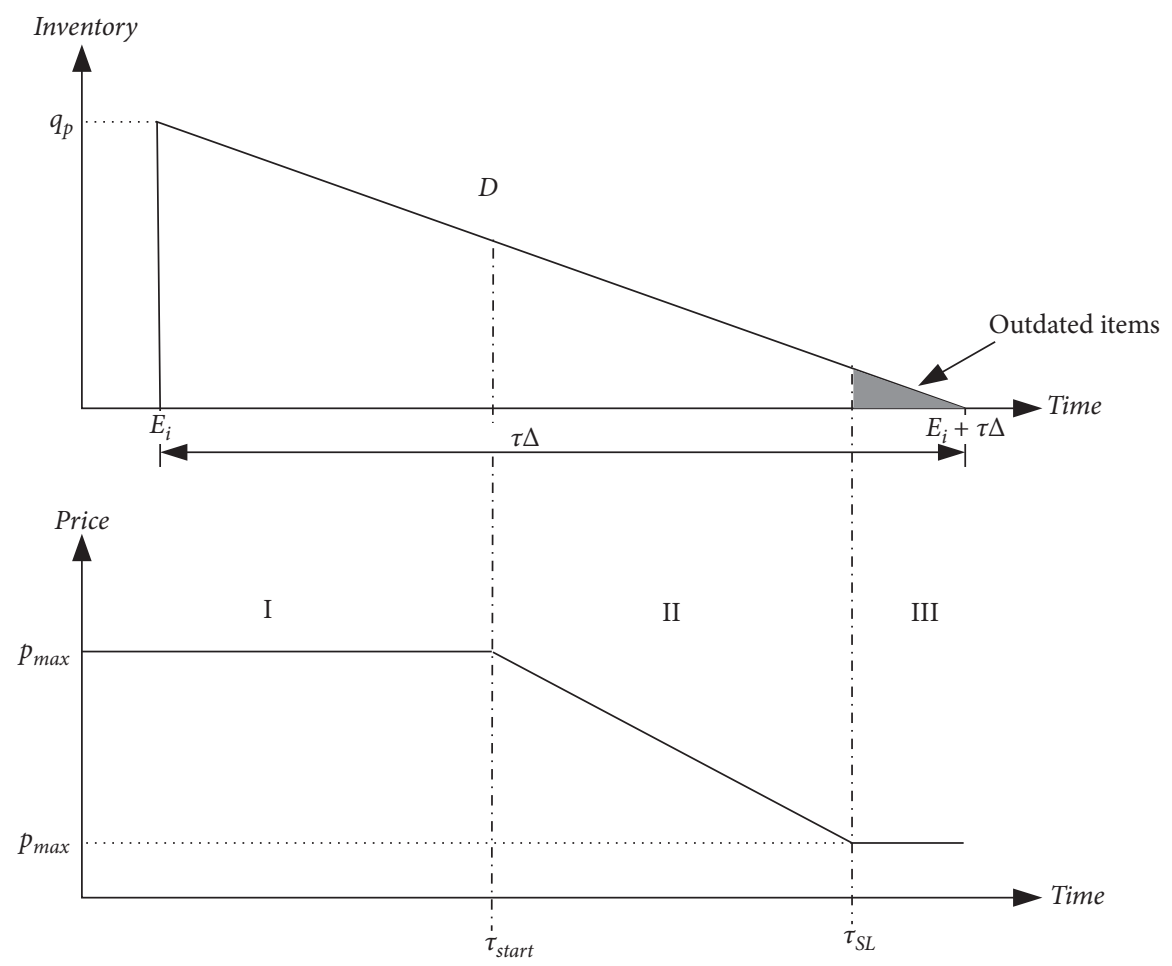

FIgURE 4: Price function based on the shelf life of each batch.

Discount prices for products are presented in region II. Meanwhile, products that have expired (reaching $\tau_{\text {sl }}$ ) are set at the lowest price of $p_{\min }$ (region III). The price reduction policy is formulated using (12) based on a model proposed by Fauza et al. [29].

$$
\begin{aligned}
& p(t)= \begin{cases}p_{\max }, & \\
p_{\min }+\frac{p_{\text {max }}-p_{\text {min }}}{\tau_{s l}-\tau_{\text {start }}}\left(\tau_{s l}-t\right), & \\
p_{\text {min }}, & \text { region I, } \\
0 \leq t<\tau_{\text {Start }}, & \text { region II, } \\
\tau_{\text {Start }} \leq t<\tau_{s l}, & \text { region III } \\
t \geq \tau_{s l}, & \end{cases} \\
& E_{i}=(i-1) \frac{T}{n}-(i-2) \frac{\mathrm{DT}}{n P} \\
& R_{i}(n, T)=\frac{D}{T} P_{\max } \tau_{\Delta}, \\
& R_{i}(n, T)=\frac{D}{T}\left[P_{\max }\left(\tau_{\text {Start }}-E_{i}\right)+\int_{\tau_{\text {Start }}}^{E_{i}+\tau_{\Delta}} p(t) \mathrm{d} t\right],
\end{aligned}
$$

$$
\begin{aligned}
R_{i}(n, T)= & \frac{D}{T}\left[P_{\max }\left(\tau_{\text {Start }}-E_{i}\right)+\int_{\tau_{\text {start }}}^{\tau_{s l}} p(t) \mathrm{d} t\right. \\
& \left.+p_{\min }\left(E_{i}+\tau_{\Delta}-\tau_{s l}\right)\right] .
\end{aligned}
$$

Buyers accept batches that have Ei less than the $\tau$ Start to earn more revenue. The batch age $(E i)$ is denoted in equation (13). Each batch $i$ received by the buyer follows the following 3 cases according to the time the product was last consumed $(E i+\tau \Delta)$. When $E i+\tau \Delta<\tau$ Start, then the revenue per year obtained from this batch can be estimated by equation (14). When $\tau$ Start $\leq(E i+\tau \Delta)<\tau_{-} s l$, the revenue per year from the batch is formulated in equation (15). Finally, when $E i+\tau \Delta \geq \tau s l$, the annual revenue function of this batch is formulated in equation (16).

(17) formulates the Joint Total Revenue in the JTR $(T, n)$ system on the I-SVSB-IP. JTR $(T, n)$ is formulated as total revenue at the vendor and buyer levels.

$$
\operatorname{JTR}(T, n)=c_{\text {sale }} D+\sum_{i=1}^{n} R_{i}(T, n) .
$$

Total profit is calculated based on the total revenue ((17) subtracted by the total cost of raw material inventory at the vendor (6), the total cost of finished product inventory at vendor level ((8), and total cost of finished product inventory at buyers (11). Since non-linear integer programming problems are difficult to solve with analytical solutions [9], this study proposes the metaheuristic algorithm to solve the I-SVSB-IP. The mixed-integer non-linear programming model formula for the I-SVSB-IP problem is presented as follows. 
Maximize

$\operatorname{JTP}(m, T, n)=\operatorname{JTR}(T, n)-\left(\mathrm{TC}_{r m}(m, T)+\mathrm{TC}_{p m}(T, n)+\mathrm{TC}_{p r}(T, n)\right)$,

subject to

$$
\begin{aligned}
& P \geq D, \\
& E_{i}<\tau_{\text {start }} ; \quad \text { for } i=1,2, \ldots n, \\
& T>0,
\end{aligned}
$$

$m, n>0$ (integer number).

The objective function of the I-SVSB-IP inventory model problem to maximize profit formulated in (18) is a form of constraint to ensure that the production level can fulfill all demands shown in (19). The constraint to ensure all batch $i$ (Ei) arrives at the buyer's warehouse before the initial time of deterioration of the finished product is formulated in equation (20). The constraint to ensure that the decision variable for the time during the inventory cycle $(T)$ is positive is denoted in equation (21). The constraints to ensure that the frequency of raw material orders $(m)$ and the frequency of delivery of finished products to buyers $(n)$ are not zero are presented in equation (22).

\section{Proposed Chimp Optimization Algorithm}

This section describes the proposed procedure for I-SVSB-IP optimization. Chimp Optimization Algorithm (ChOA) was proposed to optimize this problem. The food hunting behavior of chimpanzees inspired the ChOA algorithm. This algorithm was proposed by Khishe and Mosavi [42]. There were five stages of hunting behavior in chimp, namely, prey drive and chase, attack method (exploitation stage), prey attacking (utilization), prey search (exploration), and social incentive (sexual motivation). From this behavior, the prey was mainly hunted at the exploration and exploitation stage. (19) and (20) formulated the drive and chasing behavior, where iter was the number of iterations; $a, m c$, and $c$ were the coefficient vectors; $x_{\text {prey }}$ was the prey position vector; and $x_{\text {chimp }}$ was the chimp position vector. The coefficient vectors $a, m c$, and $c$ were calculated by, and (21)-(23). The value of $f$ decreased nonlinearly from 2.5 to 0 through the iteration process. $r_{1}$ and $r_{2}$ were random vectors in the range [0.1]. $m c$ was a chaotic vector calculated based on various chaotic maps that represented chimpanzee sexual motivation in the hunting process.

$$
\begin{aligned}
& d=\mid c \cdot x_{\text {prey }}(\text { iter })-m c \cdot x_{\text {chimp }}(\text { iter }) \mid, \\
& x_{\text {chimp }}(\text { iter }+1)=x_{\text {prey }}(\text { iter })-a \cdot d, \\
& a=2 \cdot f \cdot r_{1}-f \\
& c=2 \cdot r_{2}, \\
& m c=\text { Chaotic_value. }
\end{aligned}
$$

Chimps have a unique hunting behavior. The attacker chimp usually carries out the hunting process. The drivers, barriers, and chaser chimps sometimes participate in hunting for prey. To mathematically formulate chimp behavior, it is assumed that the attacker chimp is the best available solution. The drivers, barriers, and chaser chimps know better about potential prey locations. $x_{\text {Attacker }}$ is the best search agent. $x_{\text {Chaser }}$ is the second-best search agent. $x_{\text {Barrier }}$ is the third-best search agent, and $x_{\text {Driver }}$ is the fourth-best search agent. The other chimps are forced to renew their positions based on that solution according to the best chimpanzee location. This relationship is represented in (28), (29), and (30).

$$
\begin{aligned}
d_{\text {Attacker }} & =\left|c_{1} x_{\text {Attacker }}-m c_{1} \cdot x\right|, \\
d_{\text {Barrier }} & =\left|c_{2} \cdot x_{\text {Barrier }}-m c_{2} \cdot x\right|, \\
d_{\text {Chaser }} & =\left|c_{3} x_{\text {Chaser }}-m c_{3} \cdot x\right| \\
d_{\text {Driver }} & =\left|c_{4} x_{\text {Driver }}-m_{4} c x\right|, \\
x_{1} & =x_{\text {Attacker }}-a_{1}\left(d_{\text {Attacker }}\right), \\
x_{2} & =x_{\text {Barrier }}-a_{2}\left(d_{\text {Barrier }}\right), \\
x_{3} & =x_{\text {Chaser }}-a_{3}\left(d_{\text {Chaser }}\right), \\
x_{4} & =x_{\text {Driver }}-a_{4}\left(d_{\text {Driver }}\right), \\
x(\text { iter }+1) & =\frac{x_{1}+x_{2}+x_{3}+x_{4}}{4} .
\end{aligned}
$$

The chimps attack the prey and finish the hunt as soon as the prey stops moving. To mathematically model the attack process, the values of $f$ and $a$ have decreased. The value of $a$ is a random variable in the interval $[-2 f, 2 f]$. With each additional iteration, the value of $f$ decreases from 2.5 to 0 . If the random value of $a$ is in the range [-1.1], then the next chimpanzee position can be in any location.

This algorithm assumed a 50\% chance of a chimp choosing between the normal position update mechanism or the random model. This behavior was formulated in (31), where $\mu$ was a random number in $[0,1]$. Chaotic value was based on the formula proposed by Khishe and Mosavi [42]. The complete procedure of the proposed algorithm is presented in Algorithm 1.

$$
x_{\text {chimp }}(t+1)= \begin{cases}x_{\text {prey }}(t)-\text { a.d, } & \text { if } \mu<0.5, \\ \text { Chaotic_value, } & \text { if } \mu>0.5 .\end{cases}
$$

The ChOA applied by Goyal [47] is an algorithm used to solve continuous problems. As presented in Section 3, the I-SVSB-IP was categorized as mixed-integer non-linear programming. The I-SVSB-IP model was optimized based on the objective function of maximizing the Joint Total Profit. The decision variables of this problem were the inventory cycle time $(T)$, the frequency of raw material orders $(m)$, and the frequency of delivery of the finished product to the buyer $(n)$. The time decision variable during the inventory cycle $(T)$ was a real number. However, the decision variables for the frequency of delivery of the finished product to the buyer $(n)$ and the frequency of ordering raw material 


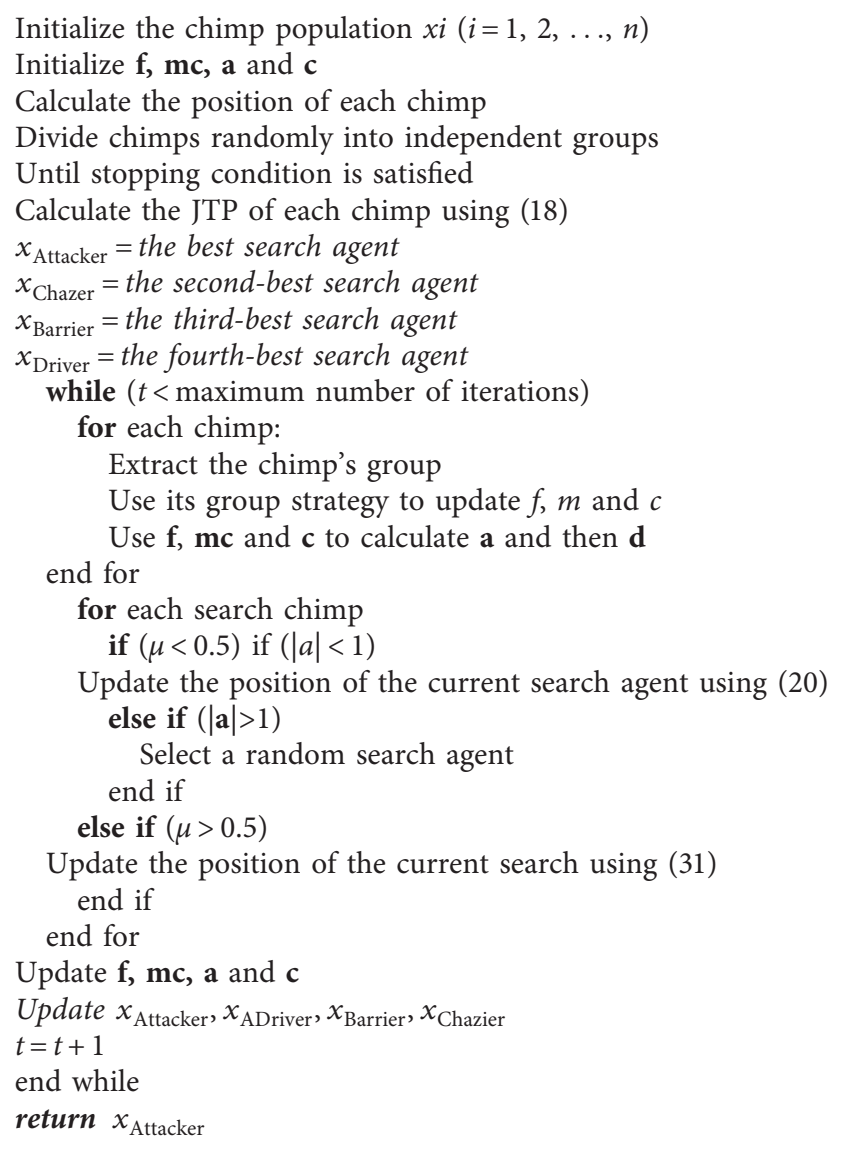

Algorithm 1: Chimp Optimization Algorithm (ChOA).

( $m$ ) were integer numbers. This study proposed a conversion procedure from real numbers to integers for the decision variables $m$ and $n$. Figure 5 shows an illustration of the decision variable conversion. If the decimal values of $m$ and $n<0.5$, then the whole number will be rounded down. Conversely, if the decimal values of $m$ and $n \geq 0.5$, then the rounded number will be rounded up.

\section{Experimental Data and Procedure}

7.1. Case Study. This study used data from a case study of a food company in Indonesia. The data collected were as follows: $P=1418 \mathrm{~kg} /$ month, $D=1298 \mathrm{~kg} / \mathrm{month}, \lambda=7.2$, Closs $=7,200 \mathrm{IDR} / \mathrm{kg}, \quad$ Csale $=85,000 \mathrm{IDR} / \mathrm{kg}, \quad C r=7,200$ IDR $/ \mathrm{kg}, C p=550 \mathrm{IDR} / \mathrm{kg}, \quad A r=50,000 \mathrm{IDR} /$ order,$\quad A p=$ 50,000 IDR/order, $S p=60,000 \mathrm{IDR} /$ installation, $H r=520$ IDR/(kg/month), $\quad H p=528 \mathrm{IDR} /(\mathrm{kg} /$ month $), \quad P \max =$ $105,000 \mathrm{IDR} / \mathrm{kg}, P \min =0 \mathrm{IDR} / \mathrm{kg}, A r=10,000 \mathrm{IDR} /$ order, $A p=10,000 \mathrm{IDR} /$ order, $D r=20 \mathrm{~km}, D p=30 \mathrm{~km}, v r=7 \mathrm{~km}$, $v p=8 \mathrm{~km}, \beta r=7,650 \mathrm{IDR} /$ liter, $\beta p=7,650 \mathrm{IDR} / \mathrm{liter}, k=0,5$, $\tau s l=8$ months, and $\tau$ Start $=6$ months.

7.2. Experimental Procedure. This section describes the experimental procedure on the I-SVSB-IP model. In optimization with the ChOA, this experiment exercised 100 search

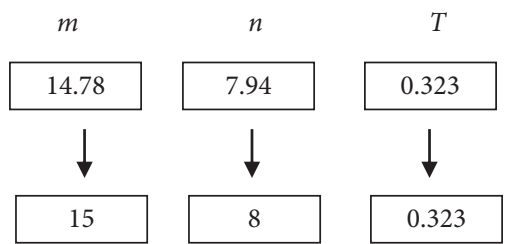

FiguRE 5: Illustration of decision variable conversion.

agents as the population and 100 iterations. The three dimensions used in the ChOA were the frequency of delivery of the finished product $(n)$, the frequency of ordering raw materials $(m)$, and the time of the production cycle $(T)$. The upper and lower limits were used as the value limits for the decision variables. The values for the upper and lower bounds of $n$ and $m$ had a range of 1 to 100. Furthermore, T's values for the upper and lower bounds were real numbers ranging from 0 to 1 .

The optimization results with ChOA were compared with state-of-the-art algorithms such as GA, PSO, and SA. In the GA, the parameters used were population $=100$, iteration $=100$, crossover rate $=0.7$, and mutation $=0.2$. For the PSO algorithm, the parameters used were particle $=100$, iteration $=100$, and inertia weight $=0.5$. Furthermore, the HS parameter used population $=100$ and iteration $=100$. 
This comparison was used to test the performance of the proposed algorithm.

The decision variables from the optimization of the I-SVSB-IP model with ChOA were used as sensitivity analyses. There were two parts of the sensitivity analysis, including (1) the influence of the variables $m, n, T$, and $k$ on cost, revenue, and Joint Total Profit and (2) the influence of transportation variables ( $a r, a p, d r, d p, v r, v p, \beta r, \beta p)$ on cost, revenue, and Joint Total Profit. In the sensitivity analysis, each variable $m, n, T$, and $k$ was treated in 9 different experiments. Furthermore, seven experiments were conducted on each transport variable ( $a r, a p, d r, d p, v r, v p, \beta r, \beta p)$. These sensitivity analyses were used to determine the effect of variables on JTP, TCrm, TCpm, TCpr, and JTR in the I-SVSB-IP model.

\section{Results and Discussion}

8.1. Optimization with ChOA and Comparison of Algorithms. The results of I-SVSB-IP optimization with ChOA can be seen in Table 2. These findings indicated that the resulting Joint Total Profit is 65,232,000 IDR. Based on the ChOA optimization results, the raw material delivery frequency $(m)$ was 15 times, the finished product delivery frequency $(n)$ was 3 times, and the production cycle time $(T)$ was 0.871 months. The results of the comparison of the algorithms are presented in Figure 6. The experimental results showed that the proposed ChOA provides more optimal results than the GA, PSO, and HS algorithms.

8.2. Sensitivity Analysis towards $m, n, T$, and $k$. The sensitivity analysis results of the effect of $m$ on cost, revenue, and profit are presented in Table 3 . These results indicated that changes in the value of $m$ do not affect TCpm, TCpr, and JTR. Furthermore, when $m$ is increased from the optimal value (15), the JTP increases, and TCrm decreases. Conversely, if $m$ is derived from the optimal value (15), then JTP decreases, and TCrm increases. This result is reasonable because the raw material has exponential quality degradation, so the higher the $m$, the lower the cost.

The sensitivity analysis results of $n$ on cost, revenue, and profit are presented in Table 4 . These results projected that changes in the value of $n$ do not affect TCrm, TCpr, and JTR. Furthermore, when $n$ is increased from the optimal value (3), the JTP and TCrm decrease further. Conversely, if $n$ is derived from the optimal value (3), JTP decreases, while TCrm increases.

The sensitivity analysis of the effect of T on cost, revenue, and profit is presented in Table 5. These results suggested that changes in the value of $T$ do not affect JTR. Furthermore, increasing $T$ from the optimal value $(0.871)$ decreases JTP while increasing TCrm, TCpm, and TCpr. Conversely, when $T$ is reduced from its optimal value $(0.871)$, JTP decreases while TCrm, TCpm, and TCpr increase.

The sensitivity analysis of the effect of $k$ on cost, revenue, and profit is shown in Table 6. These results interpreted that changes in the value of $k$ do not affect TCPm, TCpr, and JTR. In addition, when $k$ increases, JTP would certainly decrease,
TABLE 2: Results of I-SVSB-IP optimization with ChOA.

\begin{tabular}{lccc}
\hline & \multicolumn{3}{c}{ Decision variable } \\
Optimization by ChOA & $m$ & $n$ & $T$ \\
& 15 & 3 & 0.871 \\
\hline & Vendor & Buyer & Total \\
Total cost (IDR) & $69,833,000$ & $110,660,000$ & $180,493,000$ \\
Total revenue (IDR) & $110,330,000$ & $136,290,000$ & $246,620,000$ \\
Joint Total Profit (IDR) & & $65,232,000$ \\
\hline
\end{tabular}

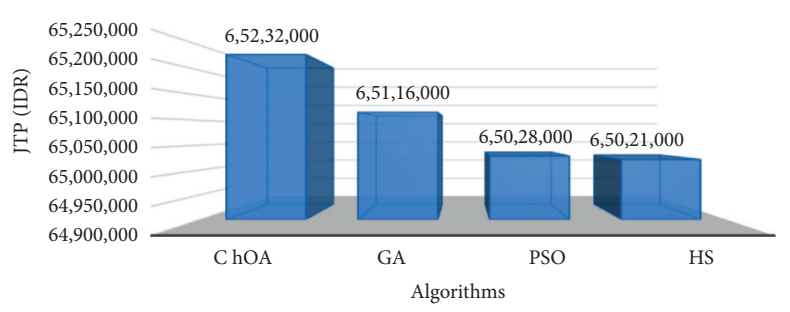

FIgURE 6: Comparison of algorithms.

and TCrm increases. Conversely, when $k$ decreases, JTP increases, and TCrm decreases.

8.3. Sensitivity Analysis of Transportation Variables (ar, ap, dr, $\mathbf{d p}, \mathbf{v r}, \mathbf{v p}, \beta \mathbf{r}, \beta \mathbf{p})$. Table 7 indicates the sensitivity analysis of the effect of ar on cost, revenue, and profit. These results asserted that when ar costs increase, JTP decreases and TCrm increases. In contrast, the lower the ar cost, the higher JTP and the lower TCrm. The increase and decrease in ar value do not affect TCpm, TCpr, and JTR. Analysis of the sensitivity of ap on cost, revenue, and profit is shown in Table 8 . The results suggested that changes in the value of ap affect the value of JTP and TCpr. Increased ap results in a decrease in JTP and an increase in TCpr. The ap cost changes do not affect TCrm, TCpm, and JTR.

The sensitivity analysis of the effect of $\mathrm{dr}$ on cost, revenue, and profit is shown in Table 9. These results confirmed that the greater the value of $\mathrm{dr}$, the smaller the value of JTP and the greater the TCrm. Changes in the value of $d r$ do not affect TCpm, TCpr, and JTR. Table 10 displays the sensitivity analysis of the effect of $d p$ on cost, revenue, and profit. These results illustrated that the greater the $d p$ value, the lower the JTP value and the higher the TCpr value. The $d p$ variable does not affect TCrm, TCpm, and JTR.

The sensitivity analysis of the effect of $v r$ on cost, revenue, and profit is shown in Table 11. The table demonstrates that as $v r$ increases, the value of JTP increases and TCrm decreases. Changes in the $v r$ value do not affect TCpm, TCpr, and JTR. Table 12 shows the sensitivity analysis of the effect of $v p$ on cost, revenue, and profit. The analysis results stated that when the $v p$ is increased, the JTP value is higher and the TCpr value decreases.

Table 13 presents the results of the influence of $\beta r$ on cost, revenue, and profit. These findings explained that as the $\beta r$ increases, the JTP decreases and the TCrm increases. The 
TABLE 3: Sensitivity analysis of the effect of $m$ on cost, revenue, and profit.

\begin{tabular}{lcccccrr}
\hline$m$ & $n$ & $T$ & JTP (IDR) & TCrm (IDR) & TCpm (IDR) & TCpr (IDR) & JTR (IDR) \\
\hline 10 & 3 & 0.871 & $64,764,000$ & $70,301,000$ & 895,000 & $110,660,000$ & $246,620,000$ \\
11 & 3 & 0.871 & $64,913,000$ & $70,152,000$ & 895,000 & $110,660,000$ & $246,620,000$ \\
12 & 3 & 0.871 & $65,028,000$ & $70,037,000$ & 895,000 & $110,660,000$ & $246,620,000$ \\
13 & 3 & 0.871 & $65,116,000$ & $69,949,000$ & 895,000 & $110,660,000$ & $246,620,000$ \\
14 & 3 & 0.871 & $65,183,000$ & $69,882,000$ & 895,000 & $110,660,000$ & $246,620,000$ \\
$\mathbf{1 5}$ & $\mathbf{3}$ & $\mathbf{0 . 8 7 1}$ & $\mathbf{6 5 , 2 3 2 , 0 0 0}$ & $\mathbf{6 9 , 8 3 3 , 0 0 0}$ & $\mathbf{8 9 5 , 0 0 0}$ & $\mathbf{1 1 0 , 6 6 0 , 0 0 0}$ & $\mathbf{2 4 6 , 6 2 0 , 0 0 0}$ \\
16 & 3 & 0.871 & $65,268,000$ & $69,797,000$ & 895,000 & $110,660,000$ & $246,620,000$ \\
17 & 3 & 0.871 & $65,293,000$ & $69,772,000$ & 895,000 & $110,660,000$ & $246,620,000$ \\
18 & 3 & 0.871 & $65,307,000$ & $69,758,000$ & 895,000 & $110,660,000$ & $246,620,000$ \\
19 & 3 & 0.871 & $65,314,000$ & $69,751,000$ & 895,000 & $110,660,000$ & $246,620,000$ \\
\hline
\end{tabular}

TABLE 4: Analysis of the sensitivity of the effect of $n$ on cost, revenue, and profit.

\begin{tabular}{lcccccrr}
\hline$m$ & $n$ & $T$ & JTP (IDR) & TCrm (IDR) & TCpm (IDR) & TCpr (IDR) & JTR (IDR) \\
\hline 15 & 1 & 0.871 & $65,021,000$ & $69,833,000$ & $1,056,000$ & $110,710,000$ & $246,620,000$ \\
15 & 2 & 0.871 & $65,214,980$ & $69,833,000$ & 932,020 & $110,640,000$ & $246,620,000$ \\
$\mathbf{1 5}$ & $\mathbf{3}$ & $\mathbf{0 . 8 7 1}$ & $\mathbf{6 5 , 2 3 2 , 0 0 0}$ & $\mathbf{6 9 , 8 3 3 , 0 0 0}$ & $\mathbf{8 9 5 , 0 0 0}$ & $\mathbf{1 1 0 , 6 6 0 , 0 0 0}$ & $\mathbf{2 4 6 , 6 2 0 , 0 0 0}$ \\
15 & 4 & 0.871 & $65,197,000$ & $69,833,000$ & 870,000 & $110,720,000$ & $246,620,000$ \\
15 & 5 & 0.871 & $65,149,000$ & $69,833,000$ & 858,000 & $110,780,000$ & $246,620,000$ \\
15 & 6 & 0.871 & $65,087,000$ & $69,833,000$ & 850,000 & $110,850,000$ & $246,620,000$ \\
15 & 7 & 0.871 & $65,023,000$ & $69,833,000$ & 844,000 & $110,920,000$ & $246,620,000$ \\
15 & 8 & 0.871 & $64,948,000$ & $69,833,000$ & 839,000 & $111,000,000$ & $246,620,000$ \\
15 & 9 & 0.871 & $64,881,000$ & $69,833,000$ & 836,000 & $111,070,000$ & $246,620,000$ \\
15 & 10 & 0.871 & $64,814,000$ & $69,833,000$ & 833,000 & $111,140,000$ & $246,620,000$ \\
\hline
\end{tabular}

TABLE 5: Sensitivity analysis of the effect of $T$ on cost, revenue, and profit.

\begin{tabular}{|c|c|c|c|c|c|c|c|}
\hline$m$ & $n$ & $T$ & JTP (IDR) & TCrm (IDR) & TCpm (IDR) & TCpr (IDR) & JTR (IDR) \\
\hline 15 & 3 & 0.2 & $62,437,000$ & $71,764,000$ & $1,039,000$ & $111,380,000$ & $246,620,000$ \\
\hline 15 & 3 & 0.3 & $64,037,000$ & $70,582,000$ & 951,000 & $111,050,000$ & $246,620,000$ \\
\hline 15 & 3 & 0.4 & $64,734,000$ & $70,082,000$ & 914,000 & $110,890,000$ & $246,620,000$ \\
\hline 15 & 3 & 0.5 & $65,070,638$ & $69,856,000$ & 896,000 & $110,797,362$ & $246,620,000$ \\
\hline 15 & 3 & 0.6 & $65,226,000$ & $69,765,000$ & 889,000 & $110,740,000$ & $246,620,000$ \\
\hline 15 & 3 & 0.7 & $65,281,000$ & $69,752,000$ & 887,000 & $110,700,000$ & $246,620,000$ \\
\hline 15 & 3 & 0.871 & $65,232,000$ & $69,833,000$ & 895,000 & $110,660,000$ & $246,620,000$ \\
\hline 15 & 3 & 0.9 & $65,213,000$ & $69,855,000$ & 892,000 & $110,660,000$ & $246,620,000$ \\
\hline 15 & 3 & 1 & $65,128,651$ & $69,944,000$ & 898,000 & $110,649,349$ & $246,620,000$ \\
\hline
\end{tabular}

TABLE 6: Sensitivity analysis of the effect of $k$ on cost, revenue, and profit.

\begin{tabular}{lccccc}
\hline$k$ & JTP (IDR) & TCrm (IDR) & TCpm (IDR) & TCpr (IDR) & JTR (IDR) \\
\hline 0.1 & $66,638,000$ & $68,427,000$ & 895,000 & $110,660,000$ & $246,620,000$ \\
0.2 & $66,460,000$ & $68,605,000$ & 895,000 & $110,660,000$ & $246,620,000$ \\
0.3 & $66,283,000$ & $68,782,000$ & 895,000 & $110,660,000$ & $246,620,000$ \\
0.4 & $66,106,000$ & $68,959,000$ & 895,000 & $110,660,000$ & $246,620,000$ \\
$\mathbf{0 . 5}$ & $\mathbf{6 5 , 9 3 0 , 0 0 0}$ & $\mathbf{6 9 , 1 3 5 , 0 0 0}$ & $\mathbf{8 9 5 , 0 0 0}$ & $\mathbf{1 1 0 , 6 6 0 , 0 0 0}$ & $\mathbf{2 4 6 , 6 2 0 , 0 0 0}$ \\
0.6 & $65,755,000$ & $69,310,000$ & 895,000 & $110,660,000$ & $246,620,000$ \\
0.7 & $65,580,000$ & $69,485,000$ & 895,000 & $110,660,000$ & $246,620,000$ \\
0.8 & $65,406,000$ & $69,659,000$ & 895,000 & $110,660,000$ & $246,620,000$ \\
0.9 & $65,232,000$ & $69,833,000$ & 895,000 & $110,660,000$ & $246,620,000$ \\
1 & $65,059,000$ & $70,006,000$ & $110,660,000$ & $246,620,000$ \\
\hline
\end{tabular}


TABLE 7: Analysis of sensitivity to the effect of ar on cost, revenue, and profit.

\begin{tabular}{lccccc}
\hline ar & JTP (IDR) & TCrm (IDR) & TCpm (IDR) & TCpr (IDR) & JTR (IDR) \\
\hline 8500 & $65,258,000$ & $69,807,000$ & 895,000 & $110,660,000$ & $246,620,000$ \\
9000 & $65,250,000$ & $69,815,000$ & 895,000 & $110,660,000$ & $246,620,000$ \\
9500 & $65,241,000$ & $69,824,000$ & 895,000 & $110,660,000$ & $246,620,000$ \\
10000 & $65,232,000$ & $69,833,000$ & 895,000 & $110,660,000$ & $246,620,000$ \\
10500 & $65,224,000$ & $69,841,000$ & 895,000 & $110,660,000$ & $246,620,000$ \\
11000 & $65,215,000$ & $69,850,000$ & 895,000 & $110,660,000$ & $246,620,000$ \\
11500 & $65,207,000$ & $69,858,000$ & 895,000 & $110,660,000$ & $246,620,000$ \\
\hline
\end{tabular}

Table 8: Sensitivity analysis of the effect of ap on cost, revenue, and profit.

\begin{tabular}{|c|c|c|c|c|c|}
\hline$a p$ & JTP (IDR) & TCrm (IDR) & TCpm (IDR) & TCpr (IDR) & JTR (IDR) \\
\hline 8500 & $65,237,000$ & $69,833,000$ & 895,000 & $110,655,000$ & $246,620,000$ \\
\hline 9000 & $65,235,000$ & $69,833,000$ & 895,000 & $110,657,000$ & $246,620,000$ \\
\hline 9500 & $65,233,000$ & $69,833,000$ & 895,000 & $110,659,000$ & $246,620,000$ \\
\hline 10000 & $65,232,000$ & $69,833,000$ & 895,000 & $110,660,000$ & $246,620,000$ \\
\hline 10500 & $65,230,000$ & $69,833,000$ & 895,000 & $110,662,000$ & $246,620,000$ \\
\hline 11000 & $65,228,000$ & $69,833,000$ & 895,000 & $110,664,000$ & $246,620,000$ \\
\hline 11500 & $65,227,000$ & $69,833,000$ & 895,000 & $110,665,000$ & $246,620,000$ \\
\hline
\end{tabular}

TABLE 9: Sensitivity analysis of the influence of $d r$ on cost, revenue, and profit.

\begin{tabular}{|c|c|c|c|c|c|}
\hline$d r$ & JTP (IDR) & TCrm (IDR) & TCpm (IDR) & TCpr (IDR) & JTR (IDR) \\
\hline 5 & $65,797,000$ & $69,268,000$ & 895,000 & $110,660,000$ & $246,620,000$ \\
\hline 10 & $65,609,000$ & $69,456,000$ & 895,000 & $110,660,000$ & $246,620,000$ \\
\hline 15 & $65,421,000$ & $69,644,000$ & 895,000 & $110,660,000$ & $246,620,000$ \\
\hline 20 & $65,232,000$ & $69,833,000$ & 895,000 & $110,660,000$ & $246,620,000$ \\
\hline 25 & $65,044,000$ & $70,021,000$ & 895,000 & $110,660,000$ & $246,620,000$ \\
\hline 30 & $64,856,000$ & $70,209,000$ & 895,000 & $110,660,000$ & $246,620,000$ \\
\hline 35 & $64,668,000$ & $70,397,000$ & 895,000 & $110,660,000$ & $246,620,000$ \\
\hline
\end{tabular}

TABLE 10: Sensitivity analysis of dp effect on cost, revenue, and profit.

\begin{tabular}{|c|c|c|c|c|c|}
\hline$d p$ & JTP (IDR) & TCrm (IDR) & TCpm (IDR) & TCpr (IDR) & JTR (IDR) \\
\hline 15 & $65,322,000$ & $69,833,000$ & 895,000 & $110,570,000$ & $246,620,000$ \\
\hline 20 & $65,292,000$ & $69,833,000$ & 895,000 & $110,600,000$ & $246,620,000$ \\
\hline 25 & $65,262,000$ & $69,833,000$ & 895,000 & $110,630,000$ & $246,620,000$ \\
\hline 30 & $65,232,000$ & $69,833,000$ & 895,000 & $110,660,000$ & $246,620,000$ \\
\hline 35 & $65,192,000$ & $69,833,000$ & 895,000 & $110,700,000$ & $246,620,000$ \\
\hline 40 & $65,162,000$ & $69,833,000$ & 895,000 & $110,730,000$ & $246,620,000$ \\
\hline 45 & $65,132,000$ & $69,833,000$ & 895,000 & $110,760,000$ & $246,620,000$ \\
\hline
\end{tabular}

TABLE 11: Sensitivity analysis of the effect of $v r$ on cost, revenue, and profit.

\begin{tabular}{|c|c|c|c|c|c|}
\hline$v r$ & JTP (IDR) & TCrm (IDR) & TCpm (IDR) & TCpr (IDR) & JTR (IDR) \\
\hline 4 & $64,668,000$ & $70,397,000$ & 895,000 & $110,660,000$ & $246,620,000$ \\
\hline 5 & $64,931,000$ & $70,134,000$ & 895,000 & $110,660,000$ & $246,620,000$ \\
\hline 6 & $65,107,000$ & $69,958,000$ & 895,000 & $110,660,000$ & $246,620,000$ \\
\hline 7 & $65,232,000$ & $69,833,000$ & 895,000 & $110,660,000$ & $246,620,000$ \\
\hline 8 & $65,326,000$ & $69,739,000$ & 895,000 & $110,660,000$ & $246,620,000$ \\
\hline 9 & $65,400,000$ & $69,665,000$ & 895,000 & $110,660,000$ & $246,620,000$ \\
\hline 10 & $65,458,000$ & $69,607,000$ & 895,000 & $110,660,000$ & $246,620,000$ \\
\hline
\end{tabular}


TABLE 12: Sensitivity analysis of the effect of $v p$ on cost, revenue, and profit.

\begin{tabular}{lccccc}
\hline$v p$ & JTP (IDR) & TCrm (IDR) & TCpm (IDR) & TCpr (IDR) & JTR (IDR) \\
\hline 5 & $65,112,000$ & $69,833,000$ & 895,000 & $110,780,000$ & $246,620,000$ \\
6 & $65,162,000$ & $69,833,000$ & 895,000 & $110,730,000$ & $246,620,000$ \\
7 & $65,202,000$ & $69,833,000$ & 895,000 & $110,690,000$ & $246,620,000$ \\
8 & $65,232,000$ & $69,833,000$ & 895,000 & $110,660,000$ & $246,620,000$ \\
9 & $65,252,000$ & $69,833,000$ & 895,000 & $110,640,000$ & $246,620,000$ \\
10 & $65,262,000$ & $69,833,000$ & 895,000 & $110,630,000$ & $246,620,000$ \\
11 & $65,282,000$ & $69,833,000$ & 895,000 & $110,610,000$ & $246,620,000$ \\
\hline
\end{tabular}

TABle 13: Sensitivity analysis of the effect of $\beta r$ on cost, revenue, and profit.

\begin{tabular}{|c|c|c|c|c|c|}
\hline$\beta r$ & JTP (IDR) & TCrm (IDR) & TCpm (IDR) & TCpr (IDR) & JTR (IDR) \\
\hline 4650 & $65,528,000$ & $69,537,000$ & 895,000 & $110,660,000$ & $246,620,000$ \\
\hline 5650 & $65,429,000$ & $69,636,000$ & 895,000 & $110,660,000$ & $246,620,000$ \\
\hline 6650 & $65,331,000$ & $69,734,000$ & 895,000 & $110,660,000$ & $246,620,000$ \\
\hline 7650 & $65,232,000$ & $69,833,000$ & 895,000 & $110,660,000$ & $246,620,000$ \\
\hline 8650 & $65,134,000$ & $69,931,000$ & 895,000 & $110,660,000$ & $246,620,000$ \\
\hline 9650 & $65,036,000$ & $70,029,000$ & 895,000 & $110,660,000$ & $246,620,000$ \\
\hline 10650 & $64,937,000$ & $70,128,000$ & 895,000 & $110,660,000$ & $246,620,000$ \\
\hline
\end{tabular}

TABLE 14: Sensitivity analysis of the effect of $\beta p$ on cost, revenue, and profit.

\begin{tabular}{|c|c|c|c|c|c|}
\hline$\beta p$ & JTP (IDR) & TCrm (IDR) & TCpm (IDR) & TCpr (IDR) & JTR (IDR) \\
\hline 4650 & $65,302,000$ & $69,833,000$ & 895,000 & $110,590,000$ & $246,620,000$ \\
\hline 5650 & $65,282,000$ & $69,833,000$ & 895,000 & $110,610,000$ & $246,620,000$ \\
\hline 6650 & $65,252,000$ & $69,833,000$ & 895,000 & $110,640,000$ & $246,620,000$ \\
\hline 7650 & $65,232,000$ & $69,833,000$ & 895,000 & $110,660,000$ & $246,620,000$ \\
\hline 8650 & $65,202,000$ & $69,833,000$ & 895,000 & $110,690,000$ & $246,620,000$ \\
\hline 9650 & $65,172,000$ & $69,833,000$ & 895,000 & $110,720,000$ & $246,620,000$ \\
\hline 10650 & $65,152,000$ & $69,833,000$ & 895,000 & $110,740,000$ & $246,620,000$ \\
\hline
\end{tabular}

value of $\beta r$ does not affect TCPm, TCpr, and JTR. Sensitivity analysis of the effect of $\beta p$ on cost, revenue, and profit is shown in Table 14. From the analysis, it can be concluded that the greater the $\beta p$, the smaller the JTP and the greater the TCpr. The value of $\beta p$ does not affect TCrm, TCpm, and JTR.

8.4. Managerial Implications. According to the findings of this study, managing production levels has a significant impact on the operational cost and profit of the built models. The company's middle management relies on this information to forecast demand accurately. It could be done by applying Collaborative Planning, Forecasting, and Replenishment (CPFR). It can improve supply chain management performance at various levels of the supply chain, including manufacturing [71], vendor-managed inventory [72], and supplier $[73,74]$. In addition, the CPFR ensures that the vocal companies and their supply chain partners have the same accurate information about demand. When all chain partners work together, they will put forth their best effort to meet demand [75].

The study also found a relation between the financial performance of the company and the length of the product's deterioration date. The result of this research show that the shorter the product's expiration date when delivered to retailers, the higher the revenue loss. As a result, management should give warehousing management a higher priority. Some warehousing methods use the expiration date of a product as a basis for arranging deliveries to retailers. For example, FEFO (First Expired First Out) warehousing management classification ensures that products are delivered based on their expiration date [76].

This study also found that a decrease in the quality of raw materials impacts a company's profits. It demonstrates that factors like temperature, air circulation, and storage conditions significantly impact the quality of food raw materials. Temperature and humidity have been shown to significantly impact the quality of perishable materials and products [77]. Since raw materials are delivered to different parties, a traceability system must be implemented to ensure that they' have all received the proper treatment. Before being delivered, raw material from previous processes should be labeled with temperature, humidity, and storage conditions information. The alternative method for ensuring the safety and quality of raw materials and finished goods would be tracking and tracing system information [78]. 
Another interesting finding is that the supplier-manufacturer and manufacturer-retailer distance affects the company's costs and profits. As a product with perishable characteristics, transportation activities affect the quality of food products [79]. Determining the correct route can reduce transportation costs, especially fuel costs [79-81]. Therefore, choosing the supplier-manufacturing and manufacturing-retailer transportation route needs to be a concern for company management to minimize costs and increase profits.

\section{Conclusion}

This study was conducted to develop an I-SVSB-IP model that considers exponential quality degradation of raw materials. The proposed model also involves transportation costs. This study succeeded in developing the I-SVSB-IP model with the ChOA as an optimization tool. The experimental results suggested that the ChOA can solve the I-SVSB-IP. In addition, the proposed ChOA has a better performance than GA, PSO, and HS. Sensitivity analysis to the decision variables $m, n, T$, and $k$ and transportation variables was also thoroughly presented. This study had limitations, including the demand for finished products, which was assumed to be deterministic and static. In addition, it was assumed that the load did not affect the fuel consumption. In further research, the demand for finished products needs to consider dynamic and probabilistic characteristics. It is seen necessary to consider the load in the estimation of fuel consumption in transportation costs.

\section{Data Availability}

The data used to support the findings of this study are included within the article.

\section{Conflicts of Interest}

The authors declare that they have no conflicts of interest.

\section{Acknowledgments}

The authors would like to thank the University of Muhammadiyah Malang for supporting the research. In addition, the authors would also like to extend their gratitude to the Department of Industrial Engineering Optimization Laboratory for providing facilities.

\section{References}

[1] P. D. Giovanni, "Smart supply chains with vendor managed inventory, coordination, and environmental performance," European Journal of Operational Research, vol. 292, no. 2, pp. 515-531, 2021.

[2] S. Saha and T. Chakrabarti, "Cost minimization policy for manufacturer in a supply chain management system with two rates of production under inflationary condition," Jurnal Teknik Industri, vol. 21, no. 2, pp. 200-212, 2020.
[3] S. Saha, "A three-echelon dual-channel supply chain model with learning effect under the return policy," Jurnal Teknik Industri, vol. 22, no. 2, pp. 155-170, 2021.

[4] D. Joshi, B. Nepal, A. P. S. Rathore, and D. Sharma, "On supply chain competitiveness of Indian automotive component manufacturing industry," International Journal of Production Economics, vol. 143, no. 1, pp. 151-161, 2013.

[5] M. F. Ibrahim, M. M. Putri, and D. M. Utama, "A literature review on reducing carbon emission from supply chain system: drivers, barriers, performance indicators, and practices," IOP Conference Series: Materials Science and Engineering, vol. 722, no. 1, Article ID 012034, 2020.

[6] D. Simchi-Levi, P. Kaminsky, E. Simchi-Levi, and R. Shankar, Designing and Managing The Supply Chain: Concepts, Strategies and Case Studies, Tata McGraw-Hill Education, New York, NY, USA, 2008.

[7] S. M. Disney and D. R. Towill, "A procedure for the optimization of the dynamic response of a Vendor Managed Inventory system," Computers \& Industrial Engineering, vol. 43, no. 1-2, pp. 27-58, 2002.

[8] D. M. Utama, I. Santoso, Y. Hendrawan, and W. A. P. Dania, "Integrated procurement-production inventory model in supply chain: a systematic review," Operations Research Perspectives, vol. 9, Article ID 100221, 2022.

[9] J. Sadeghi, S. M. Mousavi, S. T. A. Niaki, and S. Sadeghi, "Optimizing a multi-vendor multi-retailer vendor managed inventory problem: two tuned meta-heuristic algorithms," Knowledge-Based Systems, vol. 50, pp. 159-170, 2013.

[10] D. M. Utama, H. M. Kholik, and A. F. Mulya, "Integrated procurement-production inventory model with two-stage production," Jurnal Teknik Industri, vol. 21, no. 2, pp. 185-199, 2020.

[11] B. Sarkar, B. Ganguly, M. Sarkar, and S. Pareek, "Effect of variable transportation and carbon emission in a three-echelon supply chain model," Transportation Research Part E: Logistics and Transportation Review, vol. 91, pp. 112-128, 2016.

[12] R. Dekker, J. Bloemhof, and I. Mallidis, "Operations research for green logistics - an overview of aspects, issues, contributions and challenges," European Journal of Operational Research, vol. 219, no. 3, pp. 671-679, 2012.

[13] S. K. D. B. Maulana, D. M. Utama, M. S. Asrofi et al., "The capacitated sustainable EOQ models: models considering tax emissions," Jurnal Teknik Industri, vol. 21, pp. 12-21, 2020.

[14] S. M. Disney and D. R. Towill, "The effect of vendor managed inventory (VMI) dynamics on the Bullwhip Effect in supply chains," International Journal of Production Economics, vol. 85, no. 2, pp. 199-215, 2003.

[15] D. M. Utama, D. S. Widodo, M. F. Ibrahim, K. Hidayat, and S. K. Dewi, "The sustainable economic order quantity model: a model consider transportation, warehouse, emission carbon costs, and capacity limits," Journal Of Physics: Conference Series, vol. 1569, Article ID 022095, 2020.

[16] D. S. Widodo and D. M. Utama, "Analisis model sustainable economic order quantity dengan mempertimbangkan emisi karbon dan batasan Kapasitas Gudang untuk menekan total biaya persediaan," Teknik, vol. 40, no. 3, pp. 169-175, 2019.

[17] A. Sepehri, U. Mishra, and B. Sarkar, "A sustainable production-inventory model with imperfect quality under preservation technology and quality improvement investment," Journal of Cleaner Production, vol. 310, Article ID 127332, 2021. 
[18] J. T. Hsu and L. F. Hsu, "An integrated single-vendor singlebuyer production-inventory model for items with imperfect quality and inspection errors," International Journal of Industrial Engineering Computations, vol. 3, no. 5, pp. 703-720, 2012.

[19] K. S. Park, "An integrated production-inventory model for decaying raw materials," International Journal of Systems Science, vol. 14, no. 7, pp. 801-806, 1983.

[20] W. A. Jauhari and I. N. Pujawan, "Joint economic lot size (JELS) model for single-vendor single-buyer with variable production rate and partial backorder," International Journal of Operational Research, vol. 20, no. 1, pp. 91-108, 2014.

[21] S. J. Sadjadi, S. Zokaee, and N. Dabiri, "A single-vendor single-buyer joint economic lot size model subject to budget constraints," International Journal of Advanced Manufacturing Technology, vol. 70, no. 9-12, pp. 1699-1707, 2014.

[22] A. Agustiandi, Y. M. K. Aritonang, and C. Rikardo, "Integrated inventory model for single vendor multi-buyer with a single item by considering warehouse and capital constraint," Jurnal Teknik Industri, vol. 22, no. 1, pp. 71-84, 2021.

[23] M. Vijayashree and R. Uthayakumar, "A single-vendor and a single-buyer integrated inventory model with ordering cost reduction dependent on lead time," Journal of Industrial Engineering International, vol. 13, no. 3, pp. 393-416, 2017.

[24] B. C. Giri, A. Dash, and A. K. Sarkar, "A single-vendor singlebuyer supply chain model with price and green sensitive demand under batch shipment policy and planned backorder," International Journal of Procurement Management, vol. 13, no. 3, pp. 299-321, 2020.

[25] K. Fu, Z. Chen, and H. M. Wee, “Advantageous and disadvantageous inequality fairness concerns: the impact on the single-vendor single-buyer production-inventory system," International Journal of Manufacturing Technology and Management, vol. 33, no. 5, pp. 342-361, 2019.

[26] X. Wang and D. Li, "A dynamic product quality evaluation based pricing model for perishable food supply chains," Omega, vol. 40, no. 6, pp. 906-917, 2012.

[27] M.-F. Yang and W.-C. Tseng, "Deteriorating inventory model for chilled food," Mathematical Problems in Engineering, vol. 2015, Article ID 816876, 10 pages, 2015.

[28] L.-Y. Ouyang, K.-S. Wu, and C.-T. Yang, "A study on an inventory model for non-instantaneous deteriorating items with permissible delay in payments," Computers \& Industrial Engineering, vol. 51, no. 4, pp. 637-651, 2006.

[29] G. Fauza, Y. Amer, S.-H. Lee, and H. Prasetyo, “An integrated single-vendor multi-buyer production-inventory policy for food products incorporating quality degradation," International Journal of Production Economics, vol. 182, pp. 409-417, 2016.

[30] M. F. Ibrahim, Y. S. Mardhiyyah, A. Rusdiansyah, M. K. Boer, and D. M. Utama, "A three-phased perishable inventory simulation model with quality decrease consideration," Jurnal Ilmiah Teknik Industri, vol. 19, no. 2, pp. 198-211, 2020.

[31] F. Silva-Aravena, I. Ceballos-Fuentealba, and E. ÁlvarezMiranda, "Inventory management at a Chilean hospital pharmacy: case study of a dynamic decision-aid tool," Mathematics, vol. 8, no. 11, p. 1962, 2020.

[32] D. Shen, K. K. Lai, S. C. H. Leung, and L. Liang, "Modelling and analysis of inventory replenishment for perishable agricultural products with buyer-seller collaboration," International Journal of Systems Science, vol. 42, no. 7 , pp. 1207-1217, 2011.
[33] G. Fauza, H. Prasetyo, and B. S. Amanto, "An integrated production-inventory model for food products adopting a general raw material procurement policy," IOP Conference Series: Materials Science and Engineering, vol. 352, Article ID 012013, 2018.

[34] G. Fauza, H. Prasetyo, N. K. Dania, and B. S. Amanto, "Development of food inventory model in an integrated vendor-buyer system: case study in food industry," AIP Conference Proceedings, vol. 1977, Article ID 020053, 2018.

[35] S. H. R. Pasandideh, S. T. A. Niaki, and A. R. Nia, "A genetic algorithm for vendor managed inventory control system of multi-product multi-constraint economic order quantity model," Expert Systems with Applications, vol. 38, no. 3, pp. 2708-2716, 2011.

[36] J. Sadeghi, A. Sadeghi, and M. S. Mehrabad, "A parametertuned genetic algorithm for vendor managed inventory model for a case single-vendor single-retailer with multi-product and multi-constraint," Journal of Optimization in Industrial Engineering, vol. 4, no. 9, pp. 57-67, 2011.

[37] A. A. Taleizadeh, S. T. A. Niaki, N. Shafii, R. G. Meibodi, and A. Jabbarzadeh, "A particle swarm optimization approach for constraint joint single buyer-single vendor inventory problem with changeable lead time and (r,Q) policy in supply chain," International Journal of Advanced Manufacturing Technology, vol. 51, no. 12, pp. 1209-1223, 2010.

[38] A. A. Taleizadeh, M. B. A. Bahador, and S. T. A. Niaki, "Optimizing multi-product multi-constraint inventory control systems with stochastic replenishments," Journal of Applied Sciences, vol. 8, no. 7, pp. 1228-1234, 2008.

[39] K. S. Lee and Z. W. Geem, "A new structural optimization method based on the harmony search algorithm," Computers \& Structures, vol. 82, no. 9-10, pp. 781-798, 2004.

[40] M. Laumanns, L. Thiele, K. Deb, and E. Zitzler, "Combining convergence and diversity in evolutionary multiobjective optimization," Evolutionary Computation, vol. 10, no. 3, pp. 263-282, 2002.

[41] A. A. Taleizadeh, S. T. A. Niaki, and M.-B. Aryanezhad, “A hybrid method of Pareto, TOPSIS and genetic algorithm to optimize multi-product multi-constraint inventory control systems with random fuzzy replenishments," Mathematical and Computer Modelling, vol. 49, no. 5-6, pp. 1044-1057, 2009.

[42] M. Khishe and M. R. Mosavi, "Chimp optimization algorithm," Expert Systems with Applications, vol. 149, Article ID 113338, 2020.

[43] M. Khishe and M. R. Mosavi, "Classification of underwater acoustical dataset using neural network trained by Chimp Optimization Algorithm," Applied Acoustics, vol. 157, Article ID 107005, 2020.

[44] M. Kaur, R. Kaur, N. Singh, and G. Dhiman, "SChoA: a newly fusion of sine and cosine with chimp optimization algorithm for HLS of datapaths in digital filters and engineering applications," Engineering with Computers, pp. 1-29, 2021.

[45] M. Bonney and M. Y. Jaber, "Environmentally responsible inventory models: non-classical models for a non-classical era," International Journal of Production Economics, vol. 133, no. 1, pp. 43-53, 2011.

[46] A. Banerjee, "A joint economic-lot-size model for purchaser and vendor," Decision Sciences, vol. 17, no. 3, pp. 292-311, 1986.

[47] S. K. Goyal, "A joint economic-lot-size model for purchaser and vendor: a comment," Decision Sciences, vol. 19, no. 1, pp. 236-241, 1988. 
[48] S. K. Goyal and Y. P. Gupta, "Integrated inventory models: the buyer-vendor coordination," European Journal of Operational Research, vol. 41, no. 3, pp. 261-269, 1989.

[49] R. M. Hill, “The optimal production and shipment policy for the single-vendor singlebuyer integrated production-inventory problem," International Journal of Production Research, vol. 37, no. 11, pp. 2463-2475, 1999.

[50] L. Lu, "A one-vendor multi-buyer integrated inventory model," European Journal of Operational Research, vol. 81, no. 2, pp. 312-323, 1995.

[51] R. M. Hill and M. Omar, "Another look at the single-vendor single-buyer integrated production-inventory problem," International Journal of Production Research, vol. 44, no. 4, pp. 791-800, 2006.

[52] M. A. Ben-Daya and A. Raouf, "Inventory models involving lead time as a decision variable," Journal of the Operational Research Society, vol. 45, pp. 579-582, 1994.

[53] L. Y. Ouyang, N. C. Yeh, and K. S. Wu, "Mixture inventory model with backorders and lost sales for variable lead time," Journal of the Operational Research Society, vol. 47, no. 6, pp. 829-832, 1996.

[54] Y. Yao, P. T. Evers, and M. E. Dresner, "Supply chain integration in vendor-managed inventory," Decision Support Systems, vol. 43, no. 2, pp. 663-674, 2007.

[55] T. Sekar and R. Uthayakumar, "A production inventory model for single vendor single buyer integrated demand with multiple production setups and rework," Uncertain Supply Chain Management, vol. 6, pp. 75-90, 2018.

[56] Q. Mou, Y. Cheng, and H. Liao, "A note on "lead time reduction strategies in a single-vendor-single-buyer integrated inventory model with lot size-dependent lead times and stochastic demand," International Journal of Production Economics, vol. 193, pp. 827-831, 2017.

[57] M. AlDurgam, K. Adegbola, and C. H. Glock, "A singlevendor single-manufacturer integrated inventory model with stochastic demand and variable production rate," International Journal of Production Economics, vol. 191, pp. 335-350, 2017.

[58] S. Zanoni and L. Zavanella, "Single-vendor single-buyer with integrated transport-inventory system: models and heuristics in the case of perishable goods," Computers \& Industrial Engineering, vol. 52, no. 1, pp. 107-123, 2007.

[59] S. Lee and D. Kim, "An optimal policy for a single-vendor single-buyer integrated production-distribution model with both deteriorating and defective items," International Journal of Production Economics, vol. 147, pp. 161-170, 2014.

[60] Y. Liu, Q. Li, and Z. Yang, "A new production and shipment policy for a coordinated single-vendor single-buyer system with deteriorating items," Computers \& Industrial Engineering, vol. 128, pp. 492-501, 2019.

[61] K. Fu, Z. Chen, and B. R. Sarker, "An optimal decision policy for a single-vendor single-buyer production-inventory system with leaning effect, fuzzy demand and imperfect quality," Journal of Information and Optimization Sciences, vol. 40, no. 3, pp. 633-658, 2019.

[62] I. D. Wangsa and H. M. Wee, "An integrated vendor-buyer inventory model with transportation cost and stochastic demand," International Journal of Systems Science: Operations \& Logistics, vol. 5, no. 4, pp. 295-309, 2018.

[63] I. D. Wangsa, S. Tiwari, H. M. Wee, and S. Reong, "A sustainable vendor-buyer inventory system considering transportation, loading and unloading activities," Journal of Cleaner Production, vol. 271, Article ID 122120, 2020.
[64] W. A. Jauhari, "A collaborative inventory model for vendorbuyer system with stochastic demand, defective items and carbon emission cost," International Journal of Logistics Systems and Management, vol. 29, no. 2, pp. 241-269, 2018.

[65] I. Sangal, B. Shaw, B. Sarkar, and R. Guchhait, "A joint inventory model with reliability, carbon emission, and inspection errors in a defective production system," Yugoslav Journal of Operations Research, vol. 30, no. 3, pp. 381-398, 2020.

[66] W. A. Jauhari, "Integrated vendor-buyer model with defective items, inspection error and stochastic demand," International Journal of Mathematics in Operational Research, vol. 8, no. 3, pp. 342-359, 2016.

[67] N. Çömez-Dolgan, L. Moussawi-Haidar, and M. Y. Jaber, “A buyer-vendor system with untimely delivery costs: traditional coordination vs. VMI with consignment stock," Computers \& Industrial Engineering, vol. 154, Article ID 107009, 2021.

[68] A. Herbon, "An integrated manufacturer-buyer chain with bounded production cycle length," Operations Research Perspectives, vol. 8, Article ID 100181, 2021.

[69] A. Rong, R. Akkerman, and M. Grunow, "An optimization approach for managing fresh food quality throughout the supply chain," International Journal of Production Economics, vol. 131, no. 1, pp. 421-429, 2011.

[70] M. Tsiros and C. M. Heilman, "The effect of expiration dates and perceived risk on purchasing behavior in grocery store perishable categories," Journal of Marketing, vol. 69, no. 2, pp. 114-129, 2005.

[71] L. Zhang, H. Liu, and Z. Cai, "Addressing the consensus on information sharing in CPFR information systems: insights from manufacturer - retailer dyads," International Journal of Production Research, pp. 1-20, 2021.

[72] C. H. Glock and E. H. Grosse, "The impact of controllable production rates on the performance of inventory systems: a systematic review of the literature," European Journal of Operational Research, vol. 288, no. 3, pp. 703-720, 2021.

[73] D. M. Utama, M. S. Asrofi, and I. Amallynda, "Integration of AHP-MOORA algorithm in green supplier selection in the Indonesian textile industry," Journal of Physics: Conference Series, vol. 1933, Article ID 012058, 2021.

[74] D. M. Utama, "AHP and topsis integration for green supplier selection: a case study in Indonesia," Journal of Physics: Conference Series, vol. 1845, no. 1, Article ID 012015, 2021.

[75] D. Alptekin, A. Diyar, T. Salih, and F. E. Boran, "A holistic and structured CPFR roadmap with an application between automotive supplier and its aftermarket customer," International Journal of Advanced Manufacturing Technology, vol. 91, pp. 1567-1586, 2017.

[76] M. L. A. T. M. Hertog, I. Uysal, U. McCarthy, B. M. Verlinden, and B. M. Nicolaï, "Shelf life modelling for first-expired-firstout warehouse management," Philosophical Transactions of the Royal Society A: Mathematical, Physical \& Engineering Sciences, vol. 372, no. 2017, Article ID 20130306, 2014.

[77] M. H. Mahmood, M. Sultan, and T. Miyazaki, "Significance of temperature and humidity control for agricultural products storage: overview of conventional and advanced options," International Journal of Food Engineering, vol. 15, 2019.

[78] M. M. Aung and Y. S. Chang, "Traceability in a food supply chain: safety and quality perspectives," Food Control, vol. 39, pp. 172-184, 2014.

[79] D. M. Utama, T. A. Fitria, and A. K. Garside, “Artificial bee colony algorithm for solving green vehicle routing problems with time windows," Journal of Physics: Conference Series, vol. 1933, no. 1, Article ID 012043, 2021. 
[80] S. K. Dewi and D. M. Utama, "A new hybrid whale optimization algorithm for green vehicle routing problem," Systems Science \& Control Engineering, vol. 9, no. 1, pp. 61-72, 2021.

[81] D. M. Utama, D. S. Widodo, M. F. Ibrahim, and S. K. Dewi, “A new hybrid butterfly optimization algorithm for green vehicle routing problem," Journal of Advanced Transportation, vol. 2020, Article ID 8834502, 14 pages, 2020. 